\title{
Marijuana and chronic obstructive lung disease: a population-based study
}

\author{
Wan C. Tan MB, Christine Lo BSc, Aimee Jong BSc, Li Xing MSc, Mark J. FitzGerald MB, \\ William M. Vollmer PhD, Sonia A. Buist MD PhD, Don D. Sin MD MPH, for the Vancouver Burden \\ of Obstructive Lung Disease (BOLD) Research Group
}

\section{ABSTRACT}

Background: Our aim was to determine the combined and independent effects of tobacco and marijuana smoking on respiratory symptoms and chronic obstructive pulmonary disease (COPD) in the general population.

Method: We surveyed a random sample of 878 people aged 40 years or older living in Vancouver, Canada, about their respiratory history and their history of tobacco and marijuana smoking. We performed spirometric testing before and after administration of $200 \mu \mathrm{g}$ of salbutamol. We examined the association between tobacco and marijuana smoking and COPD.

Results: The prevalence of a history of smoking in this sample was $45.5 \%$ (95\% confidence interval $[\mathrm{CI}] 42.2 \%-48.8 \%$ ) for marijuana use and $53.1 \%(95 \% \mathrm{Cl} 49.8 \%-56.4 \%)$ for tobacco use. The prevalence of current smoking (in the past 12 months) was $14 \%$ for marijuana use and $14 \%$ for tobacco use. Compared with nonsmokers, participants who reported smoking only tobacco, but not those who reported smoking only marijuana, experienced more frequent respiratory symptoms (odds ratio [OR] 1.50, 95\% Cl 1.05-2.14) and were more likely to have COPD (OR 2.74, 95\% Cl 1.66-4.52). Concurrent use of marijuana and tobacco was associated with increased risk (adjusted for age, asthma and comorbidities) of respiratory symptoms (OR 2.39, $95 \% \mathrm{Cl}$ 1.58-3.62) and COPD (OR 2.90, 95\% Cl 1.53-5.51) if the lifetime dose of marijuana exceeded 50 marijuana cigarettes. The risks of respiratory symptoms and of COPD were related to a synergistic interaction between marijuana and tobacco.

Interpretation: Smoking both tobacco and marijuana synergistically increased the risk of respiratory symptoms and COPD. Smoking only marijuana was not associated with an increased risk of respiratory symptoms or COPD.

Une version française de ce résumé est disponible à l'adresse www.cmaj.ca/cgi/content/full/180/8/814/DC1

CMAJ 2009;180(8):814-20

annabis, commonly known as marijuana, is the most widely used illegal drug in the world. After tobacco, it is the second most widely smoked substance in the general population, with a conservatively estimated 11 million users in the United States and 160 million users worldwide. ${ }^{1,2}$ The majority of people in both developed and devel- oping countries who currently smoke tobacco have also smoked marijuana. ${ }^{3-6}$

Concerns about the impact of marijuana on lung health are based on the fact that both the gaseous and the particulate phases of tobacco and cannabis smoke contain a similar range of harmful chemicals. ${ }^{7}$ The adverse effects of tobacco smoke on the lungs are well established. By contrast, the potential impact on lung health of marijuana smoke, with its wide range of toxins, is poorly understood. ${ }^{8}$ Short-term, heavy marijuana smoking among young adults can worsen lung function. ${ }^{9}$ Longterm marijuana smoking has been linked to an increase in respiratory symptoms. ${ }^{8-11}$ A recent cross-sectional study of a convenience sample of adults in New Zealand suggested that marijuana smoking increased the risk of chronic obstructive pulmonary disease (COPD).${ }^{12}$ However, the combined effect of smoking both tobacco and marijuana is less clear. Limited data from 2 studies suggested that combined tobacco and marijuana smoking may have additive adverse respiratory effects, ${ }^{12,13}$ but the studies' findings related to lung function were inconclusive.

The principal aim of our study was to determine the combined and independent effects of tobacco smoking and marijuana smoking on the risk of respiratory symptoms and COPD among adults aged 40 years and older in the general population.

\section{Methods}

Our study was part of the population-based Burden of Obstructive Lung Disease (BOLD) Initiative in Vancouver, Canada, designed to estimate the prevalence of COPD among adults aged 40 years and older in the general population. Details of the study protocol have been described in previous publications. ${ }^{14,15}$ To the original BOLD protocol, we added a questionnaire pertaining to the use of marijuana by participants.

\section{Study population and design}

We included adults aged 40 years and older living in the health service delivery area of Vancouver, Canada. A minimum of 600 participants per site completed the full proto-

From the iCapture Centre for Cardiovascular and Pulmonary Research (Tan Lo, Jong, Xing, Sin), St. Paul's Hospital and the University of British Columbia, and the Vancouver General Hospital (FitzGerald), Vancouver, BC; the Oregon Health and Sciences University (Vollmer) and the Kaiser Permanente Center for Health Research (Buist), Portland, USA 
col of the BOLD study. The prevalence of COPD was assumed to be $15 \% .{ }^{15}$ We conducted sampling in 2 stages. First, we used random-digit dialling to identify and recruit a randomized sample of at least 1000 people. ${ }^{16}$ Recruits were then invited to the clinic to complete standardized questionnaires administered by interviewers. Demographic details were collected, and participants were asked about their respiratory health and symptoms, smoking history, quality of life, use of health care services and cardiovascular comorbidities and other respiratory diseases. We also performed spirometric testing before and after administration of a bronchodilator. ${ }^{15}$ We collected data from August 2005 to April 2006.

We obtained approval to conduct the study from the University of British Columbia and the Providence Health Care Research Ethics Board.

\section{Questionnaire on marijuana use}

To obtain details about participants' marijuana use, we used a 7-item questionnaire (Appendix 1, available at www.cmaj.ca /cgi/content/full/180/8/814/DC2).

\section{Spirometric testing}

We used a portable spirometer (EasyOne, ndd Medical Technologies, Andover, USA) to collect data on forced expiratory volume in 1 second $\left(\mathrm{FEV}_{1}\right)$ and forced vital capacity (FVC). We performed the spirometric tests before and after administering $200 \mu \mathrm{g}$ of salbutamol (also known as albuterol) in accordance with the acceptability and reproducibility criteria of the American Thoracic Society. ${ }^{15}$

\section{Definitions}

Using criteria established by the Global Initiative for Chronic Obstructive Lung Disease, ${ }^{15,17}$ we defined COPD as spirometric evidence of a ratio of $\mathrm{FEV}_{1}$ to $\mathrm{FVC}$ of less than 0.70 after bronchodilation. We defined a history of tobacco smoking as a self-reported lifetime total of at least 365 cigarettes smoked, and a history of marijuana smoking as a report of any previous smoking of marijuana. For a more clinically relevant and comparable measure of marijuana use, we defined a substantial history of marijuana smoking as the selfreported lifetime total of at least 50 marijuana cigarettes smoked. This threshold is based on a finding by Aldington and colleagues ${ }^{12}$ that the effects on lung function of smoking 1 marijuana cigarette are equivalent to the effects of smoking 2.5 to 5 tobacco cigarettes.

For both tobacco and marijuana use, we defined current smoking as any smoking within the past year. Former smokers were those who reported not having smoked for at least 1 year. Lifetime exposure to tobacco was expressed in packyears ${ }^{15}$ (i.e., the number of packs of cigarettes per day multiplied by the number of years of smoking). Lifetime exposure to marijuana was either calculated similarly as "joint-years"12 or expressed as lifetime cumulative number of marijuana cigarettes smoked. ${ }^{13}$

\section{Statistical analysis}

We did not use an a priori calculation of sample size for mari- juana exposure because the sample size was fixed according to the aims of the BOLD study. Using a post hoc analysis, we determined that, without adjustment, our study would have $95.2 \%$ power $(\alpha=0.05)$ to detect a significant effect of a history of marijuana smoking on risk of COPD. When we adjusted for the facts that more than $30 \%$ of participants who smoked marijuana also smoked tobacco and that the marijuana smokers were younger and less likely to have comorbidities,

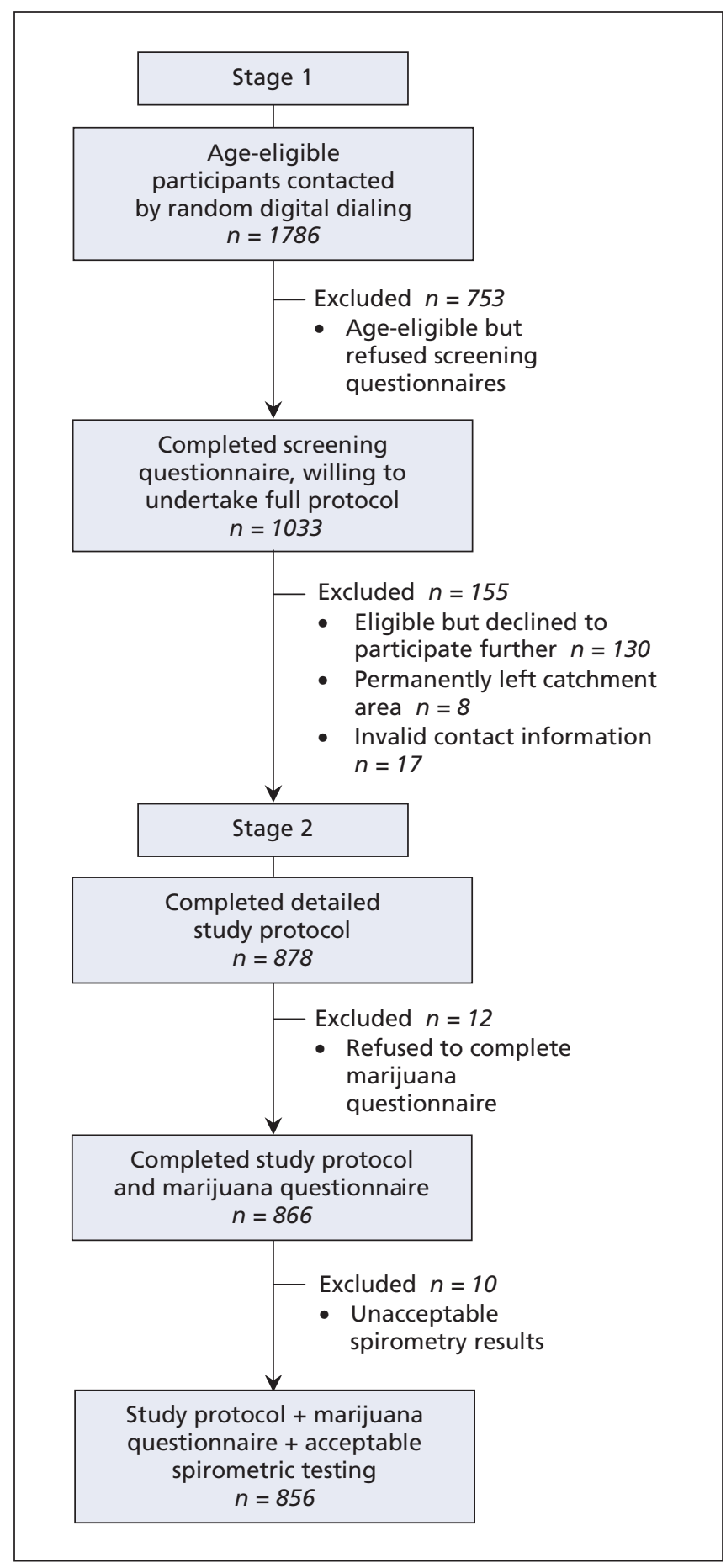

Figure 1: The 2-stage recruitment process of the Vancouver Burden of Obstructive Lung Disease (BOLD) study. 
we had $80 \%$ or greater statistical power $(\alpha=0.05)$ to detect a $15 \%$ difference in the rate of COPD between marijuana smokers and nonsmokers (of any kind), which corresponds to an adjusted odds ratio of 2.90. The observed difference, however, was 1.66 , which meant that we had insufficient power to rule out clinically important adverse respiratory effects of marijuana smoking alone.

We compared baseline characteristics using a $\chi^{2}$ test for dichotomous variables, a $t$ test or analysis of variance for continuous variables with normal distribution and a KruskalWallis test for continuous variables with a skewed distribution. Using multiple logistic regression analyses, we calculated odds ratios (ORs) with $95 \%$ confidence intervals (CIs) for associations between smoking tobacco or marijuana and increased risk of COPD, and between smoking tobacco or marijuana and increased risk of respiratory symptoms sug-

Table 1: Characteristics of the study population and prevalence of risk factors for chronic obstructive pulmonary disease (COPD)

\begin{tabular}{|c|c|c|c|}
\hline \multirow[b]{2}{*}{ Characteristic } & \multicolumn{2}{|c|}{ Study group; no. (\%) of participants* } & \multirow[b]{2}{*}{$p$ value } \\
\hline & $\begin{array}{l}\text { No COPD } † \\
n=708\end{array}$ & $\begin{array}{l}\text { COPD } \dagger \\
n=148\end{array}$ & \\
\hline Age, yr, mean (SD) & $54.3(10.7)$ & $65.4(13.1)$ & $<0.001$ \\
\hline Sex, male & $289(40.8)$ & $73(49.3)$ & 0.06 \\
\hline White & $559(79.0)$ & $132(89.4)$ & 0.004 \\
\hline Education level $\leq$ high school & $149(21.1)$ & $52(35.4)$ & $<0.001$ \\
\hline Annual income $<\$ 25000$ & $110(15.5)$ & $31(21.0)$ & 0.17 \\
\hline Body mass index & $26.6(5.3)$ & $27.0(5.1)$ & 0.38 \\
\hline Postbronchodilator $\mathrm{FEV}_{1}, \%$ predicted & $102.5(15.4)$ & $84.5(20.8)$ & $<0.001$ \\
\hline Postbronchodilator FVC, \% predicted & $101.2(15.2)$ & $104.2(19.5)$ & 0.98 \\
\hline \multicolumn{4}{|l|}{ Smoking status $\ddagger$} \\
\hline Tobacco smoker§ & $337(47.6)$ & $108(73.0)$ & $<0.001$ \\
\hline Current tobacco smokerף & $85(12.0)$ & $31(21.0)$ & 0.004 \\
\hline Current smoker of only tobacco & $57(8.1)$ & $21(14.5)$ & 0.028 \\
\hline $\begin{array}{l}\text { Lifetime tobacco dose, no. of } \\
\text { pack-years, }{ }^{* *} \text { median (IQR) }\end{array}$ & $14.0(5.0-27.5)$ & $26.6(11.9-42.8)$ & $<0.001$ \\
\hline Marijuana smokert† & $358(50.6)$ & $99(66.7)$ & $<0.001$ \\
\hline Current marijuana smoker $\ddagger$ & 105 (14.9) & $14(9.2)$ & 0.07 \\
\hline Current smoker of only marijuana & $77(11.0)$ & $4(2.7)$ & 0.003 \\
\hline $\begin{array}{l}\text { Lifetime marijuana dose, cumulative } \\
\text { no. of marijuana cigarettes smoked, } \\
\text { median (IQR) }\end{array}$ & $80.5(5.0-1111.0)$ & $208.0(10.0-1092.0)$ & $<0.001$ \\
\hline Current smoker of tobacco and marijuana & $28 \quad(3.9)$ & $10(6.5)$ & 0.33 \\
\hline \multicolumn{4}{|l|}{ Medical history } \\
\hline Current asthma & $46(6.5)$ & $22(14.9)$ & $<0.001$ \\
\hline History of asthma & $90(12.7)$ & $33(22.3)$ & 0.003 \\
\hline $\begin{array}{l}\text { Hospital admission because of } \\
\text { breathing problems }<10 \mathrm{yr}\end{array}$ & $53(7.5)$ & $19(12.8)$ & 0.033 \\
\hline Heart disease & $63(8.9)$ & $29(19.6)$ & $<0.001$ \\
\hline Hypertension & $121(17.1)$ & $50(33.8)$ & $<0.001$ \\
\hline Diabetes mellitus & $44(6.2)$ & $14(9.5)$ & 0.15 \\
\hline Tuberculosis & $19(2.7)$ & 7 (4.7) & 0.19 \\
\hline
\end{tabular}

Note: $F E V_{1}=$ forced expiratory volume in 1 second, FVC = forced vital capacity.

*Unless indicated otherwise.

tCOPD was defined as a ratio of FEV to FVC of 0.70 or less.

$\ddagger$ Participants who provided relevant information about their histories of cigarette smoking $(n=445)$ or marijuana smoking $(n=393)$.

§Participants who had smoked $\geq 365$ tobacco cigarettes.

IParticipants who had smoked tobacco within the past year.

$* *$ Pack-years $=$ the number of packs of cigarettes smoked per day multiplied by the number of years of smoking.

t+Participants who had smoked at least 1 marijuana cigarette.

$\neq \neq$ Participants who had smoked marijuana within the past year. 
gestive of COPD. For these analyses, we identified COPD by spirometric test results or by self-report of a physician's diagnosis of COPD, chronic bronchitis or emphysema. Respiratory symptoms suggestive of COPD were identified as chronic cough with phlegm and current wheezing or shortness of breath.

We forced the main predictor variables in our study model, which were no smoking (reference), marijuana smoking only, cigarette smoking only, and an interaction term of smoking marijuana and tobacco concurrently. We used a stepwise process, with a significance level of $p \leq 0.05$ for both entrance and retention of each predictor variable, ${ }^{17}$ to select the covariates age, sex, body mass index, ethnic background, education level, history of asthma (ever or current), and other comorbidities including heart disease, hypertension, stroke, diabetes and tuberculosis. We applied a Wald test to detect the significance of the interaction term of concurrent marijuana and tobacco smoking. All tests were 2tailed in nature.

\section{Results}

\section{Study population}

Details of the recruitment flow in the 2-stage sampling process are shown in Figure 1. The overall cooperation rate for the sample recruited by random-digit dialling was $51 \% .^{15}$ The Vancouver sample reflected the demographic characteristics of the population ${ }^{16}$ (Appendix 1, available at www.cmaj .ca/cgi/content/full/180/8/814/DC2).

A total of 878 participants aged 40 years and older completed the interview involving the core respiratory questionnaires and underwent spirometric testing. Of these, 866 participants (99\%) completed the questionnaire on marijuana use and 856 (98\%) also had spirometric test results that met the acceptability and reproducibility criteria of the American Thoracic Society. Of the 856 participants included in our analysis, 361 (42.2\%) were men and $692(80.8 \%)$ were white. The mean age of participants was 56.3 years (standard deviation 11.9 years).

Participants with COPD tended to be older, to be white, to

Table 2: Characteristics of study participants with a significant history of marijuana smoking

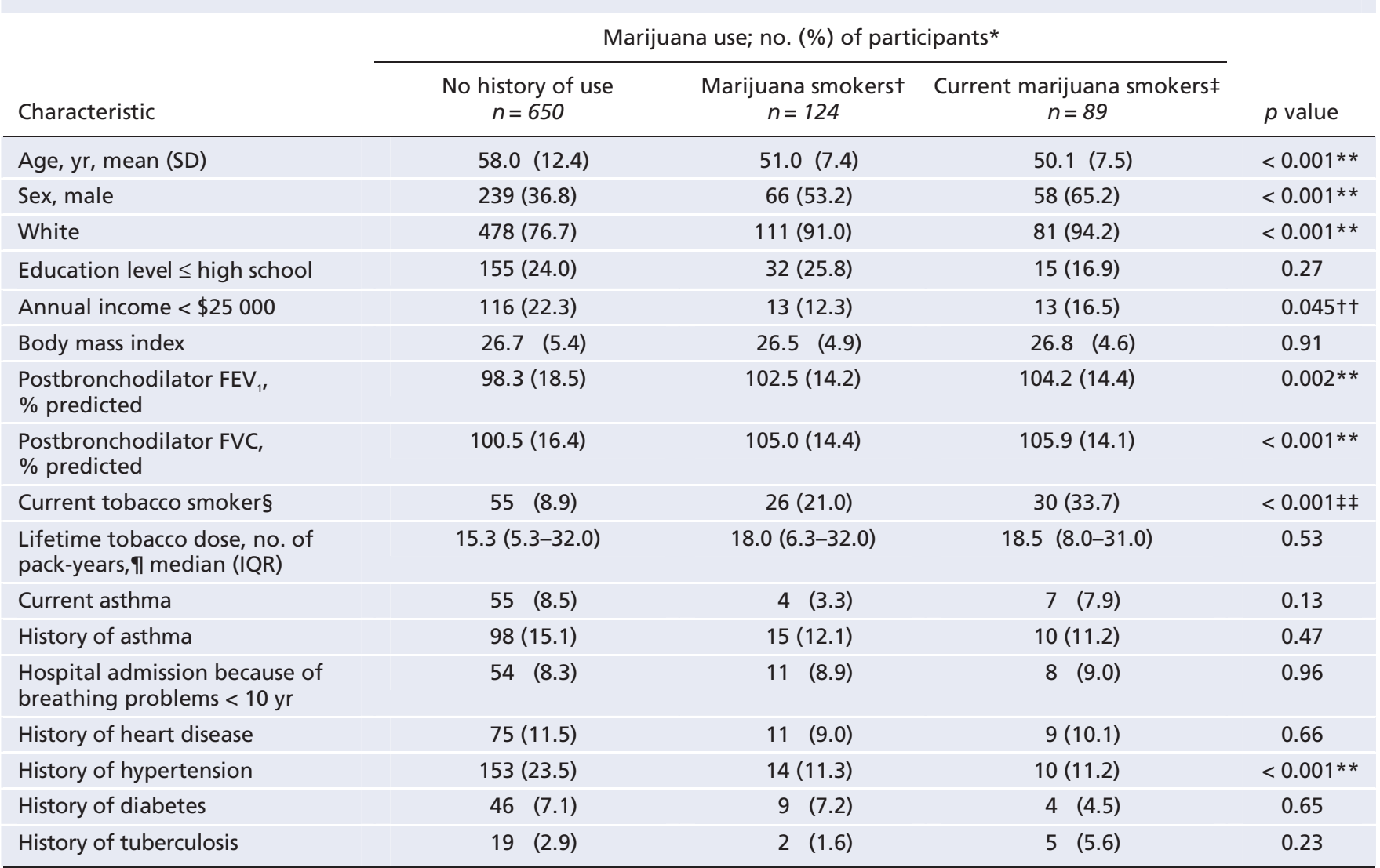

Note: FEV $_{1}=$ forced expiratory volume in 1 second; FVC = forced vital capacity.

*Unless indicated otherwise. One marijuana smoker could not be accurately classified because of a missing value in the question that pertains to current smoking status.

tParticipants who had smoked $\geq 50$ marijuana cigarettes in lifetime.

¥Participants who had smoked marijuana within the past year.

§Participants who had smoked tobacco within the past year.

ПPack-years = the number of packs of cigarettes smoked per day multiplied by the number of years of smoking.

${ }^{* *} p<0.05$ for comparison between no history of marijuana smoking and former marijuana use; $p<0.05$ for comparison between no history of marijuana smoking and current marijuana use.

$+\dagger p<0.05$ for comparison between no history of marijuana smoking and former marijuana use.

$\neq \neq p<0.05$ for comparison between no history of marijuana smoking and former marijuana use; $p<0.05$ for comparison between no history of marijuana smoking and current marijuana use; $p<0.05$ for comparison between former marijuana use and current marijuana use. 
have lower levels of education and to have a greater load of lifetime smoking exposure (expressed as pack-years for tobacco users and as total number of marijuana cigarettes smoked for marijuana users) than participants without COPD (Table 1). Participants with COPD were also more likely to have used tobacco or marijuana, to have comorbidities including asthma, cardiovascular disease and hypertension and to have a history of hospital admission for respiratory problems before 10 years of age.

The characteristics of participants who had a significant history of marijuana use (i.e., had smoked at least 50 marijuana cigarettes in their lifetime) were compared with those who did not have a significant history of marijuana smoking (Table 2). Compared with those who had no history of marijuana use, both former and current marijuana smokers tended to be younger and to have higher income levels. They were more likely to be male, white and current smokers of tobacco, and less likely to have a history of hypertension or diabetes. They also had significantly greater baseline lung function (in terms of percentage of predicted $\mathrm{FEV}_{1}$ and percentage of predicted FVC, $p<0.001$ ) (Figure 2) (Appendix 2, available at www.cmaj.ca/cgi/content/full/180/8/814/DC2).

\section{Prevalence of COPD and tobacco or marijuana use}

The prevalence of smoking among adults aged 40 years and older was $13.5 \%$ (95\% CI 11.1\%-15.9\%) for current tobacco smokers and $53.1 \%$ (95\% CI 49.8\%-56.4\%) for those who had a history of tobacco smoking. The prevalence of smoking was $14.0 \%$ (95\% CI $11.6 \%-16.4 \%)$ for current marijuana smokers and $45.5 \%$ (95\% CI $42.2 \%-48.8 \%$ ) for those who had a history of marijuana smoking. For smokers of tobacco only and smokers of both tobacco and marijuana, the median lifetime dose of tobacco was 16 pack-years. For smokers of marijuana only and smokers of both tobacco and marijuana, the median lifetime dose of marijuana was 0.23 joint-years, or 84 marijuana cigarettes (Appendix 3, available at www.cmaj .ca/cgi/content/full/180/8/814/DC2).

The prevalence of COPD, defined by spirometric testing, was $19.3 \%(95 \%$ CI $16.36 \%-22.24 \%)$ for all 4 stages of COPD defined according to the criteria of the Global Initiative for Chronic Obstructive Lung Disease. ${ }^{15,17}$ For COPD defined as stages 2 to 4 , the prevalence was $8.2 \%(95 \% \mathrm{CI}$ $6.24 \%-10.16 \%$ ). For COPD defined by self-reporting of a physician's diagnosis, the prevalence was $7.4 \%(95 \% \mathrm{CI}$

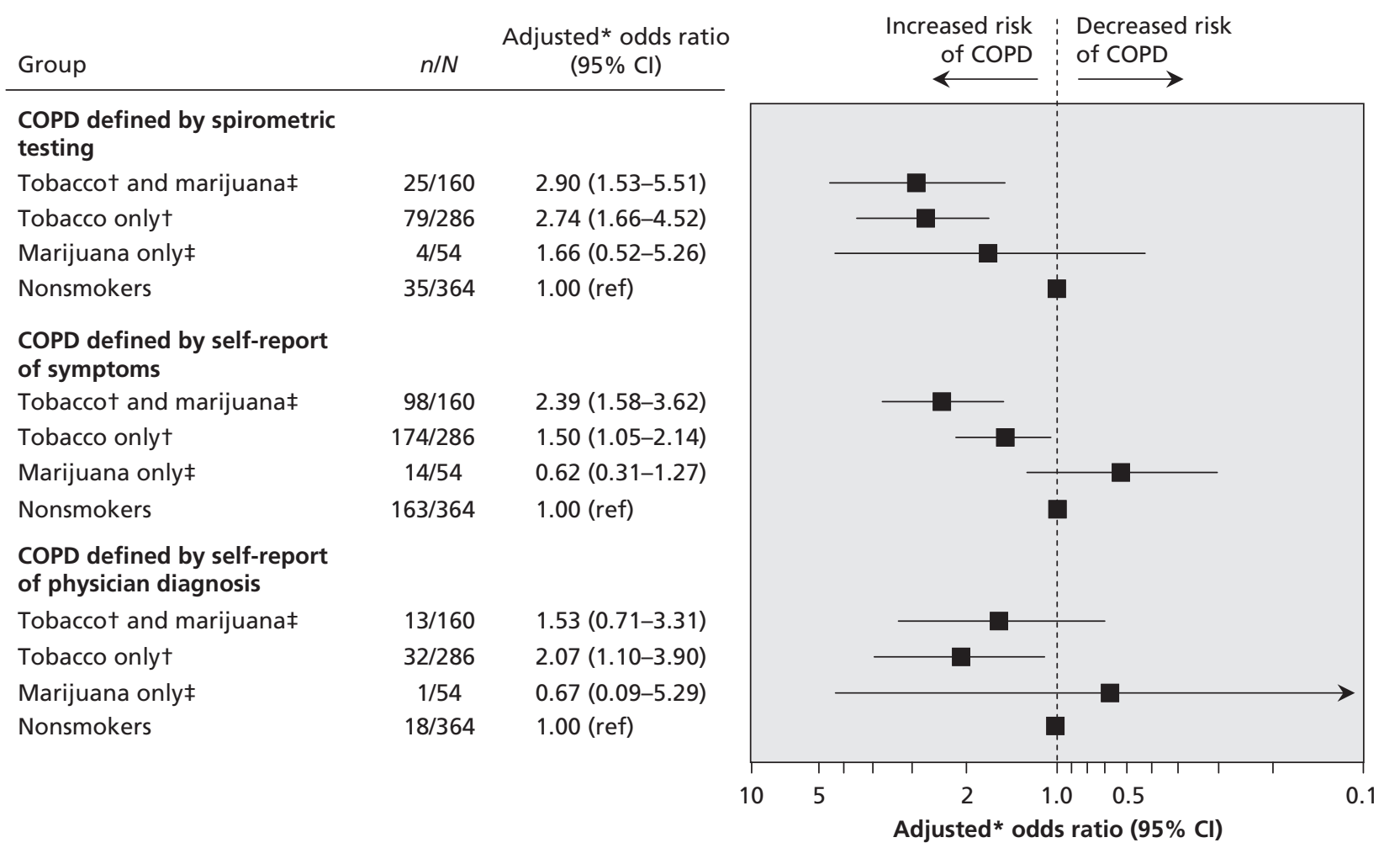

Figure 2: Risk of chronic obstructive pulmonary disease (COPD) among participants with a history of marijuana smoking, tobacco smoking or both. COPD was defined in 3 ways: by spirometric testing (ratio of forced expiratory volume in 1 second [FEV ${ }_{1}$ ] to forced vital capacity [FVC] of 0.70 or less), by self-report of respiratory symptoms (presence of chronic cough with phlegm and current wheezing or shortness of breath) and by self-report of a physician's diagnosis of COPD, chronic bronchitis or emphysema. Note: ref $=$ reference group. *Adjusted for age, sex, ethnic background, body mass index, education, asthma and other comorbidities (i.e., heart disease, hypertension, stroke, diabetes and tuberculosis) and interaction terms for concurrent smoking of marijuana and tobacco ( $p=0.001$ for COPD defined by spirometric testing, $p=0.283$ for COPD defined by self-reported symptoms, and $p<0.001$ for COPD defined by selfreport of a physician's diagnosis). †Participants who had smoked at least 365 tobacco cigarettes. $¥$ Participants who had smoked at least 50 marijuana cigarettes. 
$5.64 \%-9.16 \%)$. For respiratory symptoms, the prevalence was $52.6 \%$ (95\% CI $49.27 \%-55.93 \%)$.

\section{Association between smoking and COPD or respiratory symptoms}

For participants who reported smoking tobacco, the adjusted OR of COPD was 2.74 (95\% CI 1.66-4.52). The adjusted OR of respiratory symptoms was 1.50 (95\% CI 1.05-2.14) for these participants. Participants who had smoked at least 50 marijuana cigarettes but had no history of tobacco smoking were not at significantly greater risk for either outcome. Those who had smoked both tobacco and marijuana had a significantly greater risk of COPD (OR 2.90, 95\% CI 1.535.51; $p$ for interaction term 0.001 ) and respiratory symptoms (OR 2.39, 95\% CI 1.58-3.62; $p$ for interaction term $<0.001$ ) (Figure 2).

\section{Interpretation}

We examined the impact of marijuana smoking in a population-based sample by quantifying the association between marijuana smoking and COPD using 3 definitions: as defined by spirometric testing, by self-report of a physician's diagnosis and by self-report of respiratory symptoms. Smoking only tobacco was associated with an increased risk of COPD, as defined in all 3 ways. Smokers who reported using both marijuana and tobacco were almost 2.5 times more likely than nonsmokers to have respiratory symptoms and nearly 3 times more likely than nonsmokers to have COPD as defined by spirometric testing. These effects persisted even after we adjusted for potential confounders, such as age, sex, asthma and other comorbidities, and comparable tobacco exposure (in pack-years).

A dose-related effect of marijuana was suggested by our finding that a self-reported lifetime exposure to marijuana of at least 50 marijuana cigarettes was strongly associated with an increased risk of COPD. The significant interaction term suggested that the effects of marijuana and cigarette smoking were synergistic. We were unable to rule out clinically important respiratory effects of smoking only marijuana, because of insufficient statistical power. A much larger study is needed to address this critically important question.

Both the demographic characteristics of the study population (older adults in Vancouver) and the prevalence of smoking in our study differed from those in the published literature. Participants in our study were older than those in other studies to date. ${ }^{4,10,13,18}$ The prevalence of tobacco smoking in our study was comparatively lower. Marijuana use was as prevalent as tobacco use and was much higher than that previously reported for marijuana in the United States and Canada., 3,19,20

Although studies have consistently linked long-term marijuana use to increased respiratory symptoms, studies examining the role of marijuana smoking in the development of COPD have reported conflicting results. . $10,11,1,2,21,22^{2}$ The lack of an association between smoking only marijuana and COPD in our study is similar to that reported in the cross-sectional United States National Health and Nutrition Examination Sur- vey. That survey studied a younger population and defined marijuana smoking as a history of at least 100 instances of marijuana use. ${ }^{4}$ Our findings also concur with those of a longitudinal study of a convenience sample of adults in Los Angeles, United States, who smoked marijuana heavily (i.e., had a mean dose of more than 3-5 marijuana cigarettes per day). ${ }^{11}$ However, our results differ from those of a longitudinal population-based study involving adults in Tucson, United States, in which nontobacco smoking (assumed to be marijuana smoking) was associated with reductions in $\mathrm{FEV}_{1}$ and in the ratio of $\mathrm{FEV}_{1}$ to $\mathrm{FVC} .{ }^{18}$ Our findings also differ from those of a recent case-control study involving mostly male volunteers that linked a lifetime marijuana exposure of at least 5 jointyears (1825 marijuana cigarettes) with COPD. ${ }^{12}$

\section{Limitations}

Our study had several limitations. We lacked data on possible variations in the potency of marijuana smoked over a participant's lifetime, on individual differences in method of inhalation used by smokers of only tobacco and by smokers of both tobacco and marijuana, on the proportion of smokers who combine marijuana and tobacco in the same cigarette and on the concomitant use of other illegal drugs. Our study had insufficient power to detect a modest association between smoking only marijuana and increased risk of COPD. However, we were able to detect a significant synergistic effect between marijuana smoking and tobacco smoking. This effect suggests that smoking marijuana (at least in relatively low doses) may act as a primer, or sensitizer, in the airways to amplify the adverse effects of tobacco on respiratory health. Further studies are needed to test this hypothesis.

\section{Conclusion}

Our findings have implications for policy and research. Antismoking campaigns should include a reduction in marijuana use among their goals, aiming especially at those who regularly use both marijuana and tobacco.

\section{This article has been peer reviewed.}

Competing interests: Sonia Buist and William Vollmer received unrestricted educational grants for the operations centre of the Burden of Obstructive Lung Disease (BOLD) study and for other research from GlaxoSmithKline, Pfizer, Boehringer-Ingelheim, AstraZeneca, ALTANA, Novartis, Merck, Chiesi, Schering Plough and Sepracor. Several of the authors have served as advisory board members for GlaxoSmithKline (Wan Tan, Mark Fitzgerald, Sonia Buist), ALTANA, Schering Plough and Novartis (Sonia Buist), Merck (Sonia Buist, William Vollmer), Pfizer (Wan Tan, Sonia Buist) and AstraZeneca (Wan Tan, Mark Fitzgerald). Several of the authors have participated in workshops on chronic obstructive pulmonary disease funded by AstraZeneca (Wan Tan, Mark Fitzgerald, Don Sin, Sonia Buist), GlaxoSmithKline (Don Sin, Mark Fitzgerald, Sonia Buist, William Vollmer) and Merck (William Vollmer). Wan Tan received funding for the BOLD Vancouver site from AstraZeneca, Boehringer-Ingelheim, GlaxoSmithKline and Pfizer Canada. No competing interests declared for Christine Lo, Aimee Jong or Li Xing.

Contributors: Wan Tan, William Vollmer and Sonia Buist contributed to the conception and design of the study. Christine Lo and Aimee Jong acquired data or actively participated in data management. Li Xing directed the statistical analysis. Wan Tan, Mark FitzGerald and Don Sin contributed substantially to the analysis and interpretation of data and drafted the report. All of the authors revised the manuscript and approved the final version submitted for publication. 
Acknowledgements: We thank the men and women who participated in the study. We also thank Dr. James Hogg and Dr. Peter Paré for intellectual input and John McDonough for technical expertise in formatting the manuscript.

Funding: Local support for the Vancouver study was provided by unrestricted educational grants from AstraZeneca, Boehringer-Ingelheim, GlaxoSmithKline and Pfizer Canada. The BOLD initiative operation centre in Portland, Oregon, was funded by unrestricted educational grants from ALTANA, AstraZeneca, Aventis, Boehringer-Ingelheim, Chiesi, GlaxoSmithKline, Merck, Novartis, Pfizer, Schering-Plough, Sepracor and the University of Kentucky. The funding sponsors had no role in the design of the study, the collection, analysis or interpretation of the data, or the writing of the report.

\section{REFERENCES}

1. Substance Abuse and Mental Health Services Administration (SAMHSA). $\mathrm{Na}$ tional Household Survey on Drug Abuse, 1998. 2nd ICPSR version. Research Triangle Park (NC): Research Triangle Institute, Inter-university Consortium for Political and Social Research; 2000.

2. World drug report 2006. New York (NY): United Nations Office on Drugs and Crime; 2006. Available: www.unodc.org/pdf/WDR_2006/wdr2006_volume1.pdf (accessed 2009 Jan. 14).

3. Adlaf EM, Begin P, Sawka E, editors. Canadian Addiction Survey (CAS): a national survey of Canadians' use of alcohol and other drugs: prevalence of use and related harms: detailed report. Ottawa $(\mathrm{ON})$ : Canadian Centre on Substance Abuse; 2005.

4. Moore BA, Augustson EM, Moser RP, et al. Respiratory effects of marijuana and tobacco use in a U.S. sample. J Gen Intern Med 2005;20:33-7.

5. Timberlake DS, Haberstick BC, Hopfer CJ, et al. Progression from marijuana use to daily smoking and nicotine dependence in a national sample of U.S. adolescents. Drug Alcohol Depend 2007;88:272-81.

6. Faeh D, Viswanathan B, Chiolero A, et al. Clustering of smoking, alcohol drinking and cannabis use in adolescents in a rapidly developing country. BMC Public Health 2006;6:169.

7. Sparacino CM, Hyldburg PA, Hughes TJ. Chemical and biological analysis of marijuana smoke condensate. NIDA Res Monogr 1990;99:121-40.

8. Tetrault JM, Crothers K, Moore BA, et al. Effects of marijuana smoking on pulmonary function and respiratory complications: a systematic review. Arch Intern Med 2007;167:221-8.

9. Tashkin DP, Shapiro BJ, Lee YE, et al. Subacute effects of heavy marijuana smoking on pulmonary function in healthy men. N Engl J Med 1976;294:125-9.

10. Tashkin DP, Coulson AH, Clark VA, et al. Respiratory symptoms and lung function in habitual heavy smokers of marijuana alone, smokers of marijuana and tobacco, smokers of tobacco alone, and nonsmokers. Am Rev Respir Dis 1987;135:209-16.

11. Tashkin DP, Simmons MS, Sherrill DL, et al. Heavy habitual marijuana smoking does not cause an accelerated decline in $\mathrm{FEV}_{1}$ with age. Am J Respir Crit Care Med 1997; $155: 141-8$

12. Aldington $\mathrm{S}$, Williams $\mathrm{M}$, Nowitz $\mathrm{M}$, et al. The effects of cannabis on pulmonary structure, function and symptoms. Thorax 2007;62:1058-63.

13. Taylor DR, Fergusson DM, Milne BJ, et al. A longitudinal study of the effects of tobacco and cannabis exposure on lung function in young adults. Addiction 2002; 97:1055-61

14. Buist AS, Vollmer WM, Sullivan SD, et al. The Burden of Obstructive Lung Disease Initiative (BOLD): rationale and design. COPD 2005;2:277-83.

15. Buist AS, McBurnie MA, Vollmer WM, et al. International variation in the prevalence of COPD (the BOLD Study): a population-based prevalence study. Lancet 2007;370:741-50.

16. Tan W, Sin D, Balson D, et al. The burden of obstructive lung disease (BOLD) study in Vancouver, Canada - sampling and recruitment. Can Respir J 2007; 14(Suppl A):7A-9A.

17. Rabe KF, Hurd S, Anzueto A, et al. Global strategy for the diagnosis, management andprevention of chronic obstructive pulmonary disease: GOLD executive summary. Am J Respir Crit Care Med 2007;176:532-55.

18. Sherrill DL, Krzyzanowski M, Bloom JW, et al. Respiratory effects of non-tobacco cigarettes: a longitudinal study in general population. Int J Epidemiol 1991;20:132-7.

19. National Survey on Drug Use and Health. Rockville (MD): US Department of Health and Human Services, Substance Abuse and Mental Health Services Administration (SAMHSA), Office of Applied Studies; 2004. NSDUH Series H-27, DHHS Publication no. SMA 05-4061. Available: www.oas.samhsa.gov/NSDUH .htm (accessed 2009 Jan. 15).

20. Compton WM, Grant BF, Colliver JD, et al. Prevalence of marijuana use disorders in the United States: 1991-1992 and 2001-2002. JAMA 2004;291:2114-21.

21. Hernandez MJ, Martinez F, Blair HT, et al. Airway response to inhaled histamine in asymptomatic long-term marijuana smokers. J Allergy Clin Immunol 1981;67: 153-5.

22. Tashkin DP, Simmons MS, Chang P, et al. Effects of smoked substance abuse on nonspecific airway hyperresponsiveness. Am Rev Respir Dis 1993;147:97-103.

Correspondence to: Dr. Wan C. Tan, University of British Columbia, iCapture Centre for Cardiovascular and Pulmonary Research, St. Paul's Hospital, 1081 Burrard St., Vancouver BC V6Z 1Y6; fax 604 806-8351; wtan@mrl.ubc.ca

\section{Members of the Vancouver BOLD Research Group:}

Vancouver: Wan C. Tan, Christine Lo, Aimee Jong, Li Xing,

Mark J. FitzGerald, Don D. Sin, Robert S. Hogg, S.F. Paul Man,

Shen Gao, Eddy Wang, Wen Q. Gan and Jeong E. Min

Portland: Sonia A. Buist and William M. Vollmer

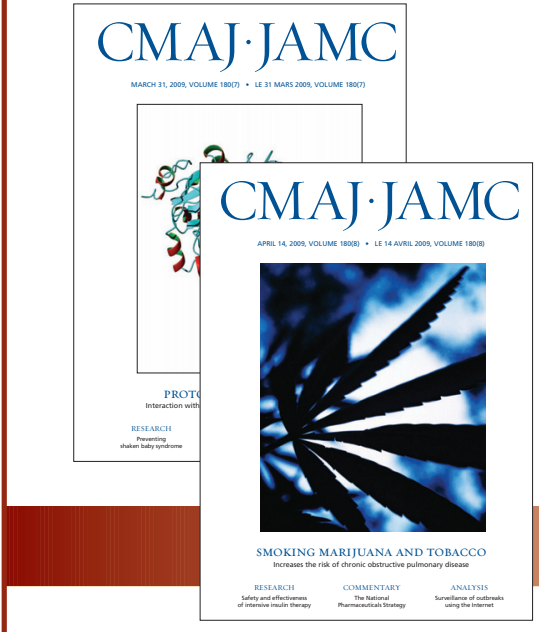

\section{Online manuscript submission and peer review available for $C M A J$}

http://mc.manuscriptcentral.com/cmaj 